\title{
The Functionalist Problem in Kraybill's Riddle of Amish Culture
}

\author{
Michael S. Billig ${ }^{1}$ \\ Professor and Chair \\ Department of Anthropology \\ Franklin \& Marshall College \\ Lancaster, PA \\ Elam Zook ${ }^{1}$ \\ Independent Consultant \\ Department of Anthropology \\ Franklin \& Marshall College \\ Lancaster, PA
}

\section{Abstract}

Much of contemporary Amish scholarship manifests an implicit functionalist paradigm that harkens back to mid-20 $0^{\text {th }}$-century social science. This perspective tends toward optimistic, even "Panglossian," explanation of traits, in which everything that the Amish do or believe has a use, purpose, or reason; i.e., a function. The vagaries of history and the ebb and flow of power may be acknowledged, but they are relegated to minor explanatory factors. This essay provides a close reading of Donald Kraybill's popular The Riddle of Amish Culture. It demonstrates the functionalist premises behind many of the explanations offered in Riddle, despite the fact that the author provides sufficient information for the reader to come to different conclusions about how aspects of Amish life came to be what they are. That the Amish themselves read and respect Kraybill's work leads to a paradoxical situation in which Kraybill's narratives are taken to be true explanations, which then become another doctrine that must not be debated or self-corrected.

\section{Keywords}

Functionalism; Explanation; Riddles; Gelassenheit; Panglossian; Consensus vs. conflict

\section{Acknowledgements}

We thank our wonderful students in ANT263 (The Amish) at Franklin \& Marshall College. And, of course, we thank our wonderfully patient wives: Heidi Wolf and Geniene Leanza. 


\section{Introduction}

With few exceptions, most social scientific writings on Amish topics maintain a justifiably discredited theoretical paradigm associated with the mid- $20^{\text {th }}$ century. This paradigm - functionalism — is often implicit rather than explicit, and it is not always obvious whether any consistent or coherent version of functionalism is being employed. There is typically little attempt at theoretical justification or argument; rather, the authors assert functional "explanations" as being obvious, intuitive, scientific, and "natural."

We will argue in this paper that while such "explanations" do satisfy many Western, especially American, cultural predilections for seeing practical reason behind the actions and beliefs of "others," they are frequently ahistorical and biased. They predispose us to viewing other people's actions and beliefs through an optimistic, Panglossian ${ }^{2}$ lens. All or most of what other people do and think may be viewed as adaptive, reasonable, useful, good, inevitable-i.e., functional. Although historical contingencies may be acknowledged, the explanations are mostly rooted in what different "traits" accomplish at the level of individual psychology, social cohesion, ecological balance, or any number of other desirable outcomes. Consensus, social cohesion, and the maintenance of stasis tend to be stressed over dynamism and conflict, which are viewed in a negative light.

As has been pointed out by many social scientists, such functionalist explanations tend to understate "life's hard edges" and the interplay of power relations. They lead us to view the "other" as living in Smurf Villages rather than bubbling cauldrons of competing interests. Strong exercises of authority are assumed to be legitimate and affirmed by consensus rather than enacted by the ability to coerce subordinates despite subtle and not-so-subtle forms of resistance from below. To put it more starkly: functionalism often slides down the slippery slope into becoming an apologetics for the perspectives of the powerful, and is, in a literal sense, a conservative doctrine. All of these attributes are patently on display in the Amish Studies literature. For the purposes of this essay, we will focus on one classic example: Donald Kraybill's (2001) widely read The Riddle of Amish Culture, a book that manages to be both popular and scholarly and that is widely read by both Amish themselves and curious English.

Obviously, the two authors of this essay come from quite different perspectives. One of us (Billig) is an anthropologist who has situated himself within the neo-Weberian perspective that stresses keeping one's value judgments out of one's social science as much as is humanly possible (see, e.g., Billig 2003). The other (Zook) is a non-compliant, Amish-raised person who has spent much of the last decade as an avowed advocate on Amish issues. We disagree about many things despite the fact that we have a productive and warm collaboration. But on the question of a functionalist theoretical stance and its intended and unintended consequences, we are (mostly) of one mind. But just in case, the final section of this essay prior to the conclusions will be Zook expressing himself entirely in his own voice. 


\section{Riddles}

Kraybill's Riddle of Amish Culture is a contradictory book. The first ten chapters-about two-thirds of the book - are highly Panglossian and functionalist, explaining virtually all of the "riddles" by elucidating how various "traits" add positively to social cohesion. The last four chapters, however, are more scholarly and balanced, often mentioning conflict, potential social disruptions, and the interplay of power. At times, he even expresses a less sanguine assessment of the Amish future. Kraybill seems not to notice the contradiction between these two parts, and he seems not to imagine that his readers would notice.

The overarching trope of Kraybill's book is, of course, riddles: aspects of Amish culture, society, and beliefs that seem strange or inexplicable to outsiders: "Idyllic from afar, Amish culture is teeming with riddles upon closer inspection. Outsiders are often baffled by the logic, or apparent absence of it, in Amish culture” (Kraybill 2001, 1). Riddles need to be solved, which in this case means to be explained rather than changed or fixed. Not only do outsiders crave the solutions to the riddles-frequently asking, "Why?"- -but in many cases, such as the prohibition on bicycles but not souped-up scooters, so too do the Amish themselves (p. 2).

To the question, "Is there a logic beneath this cultural hodgepodge-a hidden web of meaning that explains the confusing conundrums?" the answer is an emphatic Yes: "From behind the curtain, many of the puzzles appear to be ingenious solutions to the practical dilemmas faced by a group struggling to retain its traditional values amidst a rapidly changing world" (p. 3). Not only is the world rapidly changing, but also "modernization" is wreaking "cultural devastation" on "traditional cultures," the Amish among them (p. 1).

Many of the "traits" we see among the Amish may be explained as functional responses that preserve consensus, order, and organization and stave off the specters of worldliness and conflict in the face of these rapid changes. To prevent "fragmentation" and excessive individualism (p. 19), the "Aspirations, whims, and rights of individual members must be sacrificed for the common good” (p. 21). The response to the "de-contextualization” (p. 19) attendant to modernity is to ban photography, television, and telephones. "Defensive groups" (such as the Amish) must stress collective goals- “obedience, surrender, sacrifice, commitment, and discipline” — ahead of individual ones (p. 22).

In a two page functionalist blizzard, limiting "God's blessing of peace and eternal life" only to the "obedient," having “decisive leadership (to) speed decision making and offer security," and "having a system of social rewards and punishments ... to keep members compliant with groups norms” (pp. 22-23) are all necessary to maintain social cohesion and resist the temptations of the wider world. All this is seen as being analogous to the strategies taken by "teams facing aggressive opponents, corporations battling stiff competition, and armies engaged in combat” (p. 23). Even the short section about the history of Amish schisms concludes 
that, "In retrospect, the expulsion of dissidents served useful social functions over the years" (p. 26).

Although the main thrust of Riddle is to explain specific traits by their specific functions, the book also suggests a grand explanation for Amish culture in general. "The solution to the riddle of Amish culture is embedded in the German word Gelassenheit” (p. 29; boldface ours, italics in original). "Gelassenheit is a master cultural disposition, deeply bred into the Amish soul, that governs perceptions, emotions, behavior, and architecture” (p. 29; italics ours).

For a word that is "rarely used in speech" and is "an abstract concept," Kraybill pushes Gelassenheit about as far as it could go; many Amish people do not even know what the word means. What at first seems to be a Weberian ideal type takes on a reified existence capable of exerting action on people. "The submissive posture of Gelassenheit discourages higher education, abstract thinking, competition, professional occupations, and scientific pursuits” (p. 31; italics ours). Gelassenheit, this active abstraction, "recycles" ("individual energy for community purposes...”), “regulates” (“the entire spectrum of life...”), “blends” (several traits together) (p. 32), and "prefers” (“small-scale things”) (p. 106). ${ }^{3}$

One photograph of an Amish man smiling is labeled "the contented smile of Gelassenheit” (p. 35); another photo of four Amish men being prosecuted for refusal to send their children to high school states that the fathers are showing "the resignation of Gelassenheit" (p. 42). Later, Kraybill asks, "What is the organizational shape of Gelassenheit” (p. 80). Again, this ideal type abstraction seemingly possesses its own volition and is being pushed to serve too many explanatory purposes.

Kraybill explains acts of discipline as being acts of love. "A father spanks his child out of love. A bishop expels and shuns a member in 'hopes of winning him back”" (p. 39). About the method of choosing clergy by "divine mandate," he states, "It is [...] an ingenious solution to leadership selection that in a plain and simple manner confers stability, authority, and unity to community life” (p. 130-31). Of course, it barely needs to be said that the sections on excommunication and shunning strike highly functionalist chords, viewing these practices as being completely essential for the preservation of order, discipline, and social control.

Using a Durkheimian model and an old-fashioned metaphor for culture that views ritual as being somehow external to culture and society, Kraybill asserts:

Religious rituals fuse culture and structure into social music. Without ritual, a group’s culture and structure are static - like an orchestra frozen on stage. For example, culture exists in the minds of the musicians; the players understand the musical notation and they know how to play their instruments. Structure is present on the stage as well. Arranged carefully in their proper sections, the musicians face the conductor. But there is no ritual, no interaction, no music until the conductor's baton signals the start of the performance- the ritualized interaction. Cultural knowledge and structural architecture suddenly blend into music. In similar fashion, the rituals of interaction combine culture and structure 
into a social symphony of Amish life. (p. 111; italics ours)

The assertion that culture and structure are static without ritual is undermined on the very next page where Kraybill asserts, "There is one way to be baptized, one way to be married, and one way to be buried-the Amish way. The rigidity of the ritual eliminates any choice and makes the ceremonial life of the community highly predictable” (p. 112). In other words, on one page Kraybill views ritual as the source of cultural dynamism, while on the next page he sees it as leading to stasis.

As is the case with much functionalist writing, Kraybill employs hyperbole to illustrate how essential certain elements are in maintaining Amish culture and structure. Nowhere is this truer than in the section on education. "The Amish realized that the consolidated high school, designed to homogenize different cultures, would also destroy them” (p. 175). “Amish parents realized that progressive education would fracture their traditional culture” (p. 175).

Kraybill argues that the Amish-run one-room schools do an excellent job at preparing young people for life in Amish society. "Indeed, they are one of the prime reasons for the growth and vitality of Amish life” (p. 177). “Amish schools fare as well if not better than many public schools [at preparing students for life in their own society]. The vitality of Amish culture certifies the ability of its schools to prepare its pupils for a successful life in Amish society" (p. 181-82). In many places, Kraybill tells his reader that over the last several decades, the percentage of Amish young people who choose baptism has increased from around 50 percent to over 90 percent. He interprets this as a sign of "vitality," but, of course, there is an alternate explanation concerning education. Perhaps Amish education — so good at preparing students for Amish life - diminishes the choice Amish young people have by doing more poorly than it once did at preparing them for American life.

Kraybill comes close to admitting as much in his section on Rumspringa. Here the functional explanation is more about giving people the impression of choice than it is about actual choice, which is a more nuanced perspective than he evinces in his other explanations of riddles. He asserts that the "redeeming function" of Rumspringa is to serve as a type of "social immunization," in which "a minimal dose of worldliness strengthens resistance in adulthood” (p. 186).

A fling with worldliness gives Amish youth the impression that they have a choice regarding church membership [...]. The evidence, however, suggests that the perceived choice is partially an illusion. Amish youth have been thoroughly immersed in a total ethnic world with its own language, symbols, and worldview [...]. In many ways, Amish youth do not have a real choice because their upbringing and all the social forces around them funnel them toward church membership [...]. Many rowdy youth are 'reaped' later by the church in the form of obedient adults who willingly comply with the Ordnung because they believe they had a choice. (p. 186-87) 
Although Kraybill tells the reader about the history of the decision to ban telephones as a result of the 1909 schism (in which the Old Order groups banned the phone largely because the progressives opted to accept it), he still concludes that discussion with a functionalist explanation rooted in yet another "core of Amish culture”: "Although quicker and handier, the phone threatened to erode the core of Amish culture: face-to-face conversation. Thus, the restrictions on phones help to preserve separation from the outside world as well as social capital within” (p. 193; italics ours).

When the Amish refuse to compromise with modernity, Kraybill explains their refusal functionally; but he also provides functional explanations when they do compromise. Such is the case with the Amish taxi services.

In forging the car deal, the Amish gave up autonomy and independence, but some benefits come with the compromise. By permitting the use of cars, they are able to travel to distant places and conduct business in a kind of door-to-door limousine service without the typical costs of purchase and maintenance and without driving fatigue. In this way, the Amish have retained the virtues of simplicity as well as the convenience of modernity. It is a way of using modern technology without being enslaved by it or allowing it to destroy community. The use of motor vehicles has become essential for the fiscal survival of Amish industries. Moreover, it also links families and friends living in other counties and states.

Traveling by van also fosters community; it builds social capital (p. 220-21).

Since decisions are functional when the Amish resist modernity and also when they compromise with modernity, one is tempted to ask whether the Amish are even capable of making dysfunctional decisions. If the compromise allowing Amish taxis added to community in the specified ways, was the pre-compromise stance banning the taxis dysfunctional, maladaptive, or wrong-headed? Certainly not in Kraybill's explanatory universe.

In discussing the reasons for Amish success at business, Kraybill lists many obvious factors: work ethic, austerity, etc. But he also includes in this list "cultural taboos on education and certain forms of technology” (p. 258). This was only one of several sections in which Kraybill asserts that the discouragement of critical thinking serves a positive and important function for the maintenance of Amish society, a position he would likely oppose in his role as a professor teaching mainstream students.

Among Kraybill's most astonishing functional claims concerns the potential effects of the rapid transition (especially in Lancaster County) to earning income more from business than from farming. We will later argue that this transition has great potential to make significant and disruptive sociocultural changes, and Kraybill acknowledges as much later in the book. But, as usual, early on Kraybill makes the more Panglossian prediction:

In some ways, non-farm jobs have enhanced the vitality of community life. For example, they have increased Amish population density. Single-dwelling houses on small lots have greatly reduced the 
geographical size of some church districts, which enhances face-to-face interaction. This reinforces the oral base and social ties of Amish culture as well as the practicality of horse-and-buggy travel because family and friends are nearby. With fellow Amish close together, the dialect constantly reaffirms the sectarian world-view and provides a buffer against modern ways. In these ways, the occupational changes have embellished community solidarity, replenished social capital, and fortified Amish identity (p. 259).

This for a people whose lives have been predicated on agriculture for their entire existence! Even this most radical and unprecedented shift in Amish economic history is spun as having a positive function and being a cause for optimism.

\section{History and Power}

Although Kraybill has a fundamentally functionalist perspective, he is an honest enough scholar to provide most of the information necessary to reach other conclusions. His account of social change in the last few chapters of Riddle is (rather jarringly) more nuanced and dynamic than in the previous ten chapters. Whereas early in the book the theme was explaining the riddles of Amish culture with functional explanations, towards the end Kraybill asserts:

No single principle or value regulates change in Amish society; it is a dynamic process, and the outcome is always uncertain. A variety of factors impinges [sic] on any decision to accept or reject a particular practice. Decisions to move symbolic boundaries always emerge out of the ebb and flow of a fluid social matrix. The factors shaping a particular decision vary greatly (p. 297).

The information he provides about Amish history, especially schisms, gives the reader a sense of the important role that conflict and the interplay of power has had in forging Amish culture. Although much of the book espouses a "bishops' eye view” of explanation, it doesn't take very much reading between the lines to envision alternate explanations.

As early as the second chapter, Kraybill states (in a section on the role of the Bible), "Beyond their religious worldview, social control issues also come into play. Individual interpretations would quickly splinter uniform beliefs and, more importantly, the authority structure of the entire community” (p. 37). And although he equates Amish excommunication with modern society's sending people to prison, expelling illegal immigrants, and firing insubordinate employees (reifying a metaphor, to our tastes), he does refer to the ban as "the ultimate form of social control" (p. 137). Social control is an important factor in many versions of functionalism, but it is not for most of the first two-thirds of Riddle. What sets Kraybill apart from other functionalists is his insistence that all instances of social control among the Amish are necessary, virtuous, and positive.

Kraybill mostly sees the post-Wisconsin v. Yoder Amish educational system in a highly functional (and positive) light, but he admits that allowing Amish youth to learn "rational thought, critical thinking, scientific method, [and] symbolic abstraction” would enable such 
youth to "scrutinize their culture with an analytic coolness that would threaten the bishops' power" (p. 176; italics ours).

Although Kraybill mostly focuses on the "redeeming function" of Rumspringa "in the social system" (p. 186), he also admits that, "Amish youth do not have a real choice because their upbringing and all the social forces around them funnel them towards church membership" (p. 186), but that it is important for Amish youth to "believe they had a choice" (p. 187).

On a number of occasions, Kraybill admits that decisions taken by Old Order bishops were more responses to decisions by progressive or schismatic forces than purely a matter of function. "The liberals had adopted the phone, and thus the Old Orders could not accept it again without a severe loss of face. Permitting phones would be a de facto endorsement of the insurgents" (p. 191). "Fearing an unholy alliance with an evil world, steering a careful course away from the Peachey group, and bearing the imprint of a strict bishop, the electric taboo became inscribed in the Ordnung in 1920" (p. 200). "The division of 1966 erupted when the bishops tried to eradicate several pieces of farm equipment that had been in use for ten years in several church districts [...]. Questionable practices must be banned before they slip into widespread use" (p. 299). In other words, the vagaries of history and the circumstances of power matter as explanations of Amish norms.

Although Kraybill generally has a rosy view of the cultural effects of the recent occupational changes among the Amish, he does admit that, "One thing is certain: the transformation of work will change every aspect of (Amish) life" (p. 259), and, "Traditional Amish attitudes toward work and leisure will certainly change as the exodus from the farm continues" (p. 261). He asserts that, "Signs of modernity—growing individualism, control, efficiency, rationality, mobility, and occupational specialization —are clearly more and more in evidence. The rise of microenterprises is, in short, transforming the traditional culture of Amish society" (p. 309). He states that, "The recent changes seriously threaten the historic patterns of equality" (p. 109), and he acknowledges that the emergence of such inequality will likely have profound cultural effects and alter the dynamics of power. "First, managers, immersed in the daily logic of the business world, may become disenchanted [...]. Second, this emergent class represents a new, informal power structure in Amish society [...]. Business knowledge and organizational savvy arm this new breed of Amish with a power base that, if organized, could pose a serious threat to the bishops' traditional clout” (p. 264).

The bishops are not a source of innovation; instead, their duty is to inspect impending changes and resist the detrimental ones. Change in Amish society typically comes not from the top or the center of the social system, but from the periphery. It is often instigated by those living on the edge of the cultural system who try to stretch the boundaries. (p. 298)

Kraybill adds that when innovators are well-respected or wealthy people, it is more likely that their innovations will be accepted. In other words, successful businessmen are becoming the new positive reference group in many ways, and this situation may be fraught with conflict. 
The foregoing admissions about the significant changes likely to accompany the changing mode of production among the Amish are plausible and sound. Although it is true that the Amish have weathered many storms before, their agrarian economic foundation and rural ways of living have been constants since their origin. Of course, none of us possesses a crystal ball enabling us to know the future, but such transitions have happened and are continuing to happen in different places for the last 250 years, so we do have a reasonable comparative record of the impact of commodification, the emergence of new class orders, and the shift in the structures of authority, that go along with such transitions. Surely, the Amish are unlike other societies in many important ways, but it would nonetheless be unimaginable for such a shift not to be accompanied by significant and disruptive social and cultural change. After reading Chapter 10 of Riddle, Kraybill's prior assertion that the shift in occupational structure would add to social cohesion seems all the more implausible.

Although Kraybill acknowledges that most decisions in Amish society represent dynamic compromises within complex historical circumstances, he does not acknowledge that such an admission undermines the simplistic riddles-of-culture functionalism of the first two-thirds of the book.

\section{Elam Zook, In His Own Words}

Billig ably illustrates the problems with the functionalist, Panglossian view from an academic perspective. My interest is to give voice to how these views affect the actual subjects. The most immediate issue is that Kraybill's subjects are not an obscure tribe in the Amazon jungle. They not only read Kraybill's work and take it seriously, but Kraybill's work is the dominant source through which their non-Amish neighbors form their opinions of who the Amish are.

There is another way in which Kraybill's work has an outsized influence on his subjects. The Old Order Amish as we know them today, because of their authoritarian nature and the limits placed on education, have severely limited healthy critique and introspection. Kraybill's work, instead of being an enlightened outside voice, actually exacerbates that isolation by functioning as a propaganda arm for Amish authority. Since Kraybill is the renowned authority on the Amish, his work not only defines the Amish to the non-Amish world, it also carries influence in defining the Amish to themselves.

This is where Kraybill's functionalist-Panglossian view becomes dangerous. If the world renowned authority on the Amish and ninety-five percent of their non-Amish neighbors believe Amish life is, to quote Billig, a "Smurf Village," who are the Amish to disagree, especially if the Smurf Village narrative serves their leaders' interests, and they're inclined to reinforce it rather than object to it? Because of this dynamic, the Amish are unable to engage with and process their own issues. 
This, in my opinion, is what it means to be a dying society. An example of this death is Kraybill's own portrayal in which he concedes that Amish youth do not really have a choice regarding church membership. And nothing could prove this point more profoundly than when he then goes on to assert that the illusion of choice is, wait for it, "functional." Somehow, he can justify that being tricked into thinking they have a choice is a good thing for young Amish adherents. The early Anabaptists—who believed that adult baptism signified the genuine choice to join the sacred community—must be spinning in their graves!

In conclusion, the Amish need to exercise greater discernment of who their friends are. Those who say nice things about them don't necessarily have their best interests at heart.

Education must not be synonymous with indoctrination if Amish life is to be viable and self-sustaining.

Individual Amish people can believe whatever they want, but outsiders, particularly those ensconced in academia, should not have blanket immunity to function as advocates for a world view that stands in opposition to values in their own lives. For example, Kraybill acknowledges that Amish education "restricts consciousness," yet as a college professor, can't bring himself to raise the tiniest degree of doubt or concern whether there might be negative consequences to what might be more accurately described as an embrace of ignorance.

These are legitimate issues that the field of Amish studies would do well to address in a manner that brings honor to the intents and purposes of education as opposed to dishonor.

\section{Conclusion: The Problems with Functionalism}

When one of the authors of this essay (Billig) was in college in the mid-1970s, he became enamored with one of the positivist, hyper-functionalist, "high modernist" theoretical perspectives in mid-century anthropology. This perspective, called "Cultural Materialism (CM)," was closely associated with Cultural Ecology and Neo-evolutionism, and many Marxists derided it as "vulgar materialism.” The founder of this "paradigm” (as he would call it), Marvin Harris, was one of Billig's professors. Harris often referred to his ideas as demographic, technological, economic, environmental determinism (see, e.g., Harris, 2001, or in a more popular vein, Harris, 1989).

Rather than producing holistic ethnographic accounts of other people’s lives, CM was about explaining or "demystifying” the "riddles of culture" (sound familiar?); i.e., selecting seemingly bizarre or baffling, disarticulated traits among human societies (human sacrifice, cannibalism, dietary restrictions, belief in witches, believing that living monarchs are deities, etc.) and providing functional accounts that rendered these traits rational. I was dazzled by the logic of it all: (1) human beings - even when they act in bizarre ways or believe bizarre thingsare fundamentally rational; (2) they typically do not understand the rationality behind their own behaviors and beliefs, because they are mystified by culture (e.g., they believe they must perform 
human sacrifice in order to propitiate a particularly blood-thirsty god); and, (3) I can know the true rationality behind their behaviors and beliefs because I possess science (e.g., they are really performing human sacrifice because they lack essential amino acids in their diet, if you get my drift). Once we understand the function of the trait (or riddle, if you will), we have explained it. This was pretty empowering stuff for a 19-year-old!!

As happens with young anthropologists, this simplistic paradigm started to unravel soon after I began that quintessential rite of passage of my profession: field work. I went to India with a demystifying cultural materialist hypothesis identifying an overarching material cause of cultural effects and ended up concluding that I had certainly oversimplified cause and effect and perhaps had it entirely backwards. My pet causal factor was in reality a relatively minor consequence of complex historical and cultural dynamics that were not amenable to any simple, one-dimensional rationalist narrative. And the more I pondered my own research, the more it dawned on me that many CM “explanations” (including my own hypothesis) were little more than plausible sounding stories, the point of which was to render everything under the sun rational, inevitable, adaptable — in a word, functional—and then labeling these narratives "scientific."

As a graduate student, I became quite proficient at making up such stories, but seldom would there be any evidence to support such "explanations" of other people's realities. This evidence-free explanatory mode is not just true of this one brand of functionalism; it characterizes all of them.

Perhaps one could say that such high modernist theory collapsed under the weight of its own simplifications and positivist faith, having basked in the rosy optimistic glow of the American century. Although there have been some attempts in the last few decades to create neofunctionalist perspectives, most of these have not gone very far. That said, the version of functionalism evinced in the first ten chapters of Riddle is a particularly simplified and Panglossian one. There are more sophisticated versions that try (often successfully) to avoid the cloying optimism and unfailing positivity of Kraybill's version, which is handicapped by Kraybill's deep-seated Romanticism about Amish life and his insistence that the Amish may be emulated as a kind of cure for the ills of modern life.

While it may seem logical that one of the alternatives - a concentration on history and the interplay of power-leads to excessive particularism, this need not be the case, as taught by Max Weber. There are generalities to be made based on comparisons of similar phenomena in different times and different places. For example, for the last 25 years Billig's topical focus has been societies experiencing transitions from domination by rural, agrarian, land owning elites to domination by urban, industrial, commercial, and financial elites. He wrote a book (Billig 2003) and many articles on Philippine sugar, a contemporary example of such a transition, and this in significant measure is why he is now so fascinated by the Amish in Lancaster County. Of course, as we stated earlier, history is unpredictable, and the Amish are an idiosyncratic example, to say 
the least. But to assert that the Amish would be able to undergo their current economic shift without experiencing radical and disruptive social and cultural change belies everything we know about similar transitions in many parts of the world for the last several centuries. ${ }^{5}$

The functionalist perspective tacitly views stasis and consensus as normal conditions, which is why functionalists in the past have been so enamored with such terms as equilibrium, homeostasis, solidarity, and the "preservation of order." Conflict has been viewed as unhealthy, undermining of social solidarity, and even pathological. The virtue of eliminating those who upset the social order or refuse to conform to social rules and norms has been a functionalist theme well before Kraybill. Kraybill's position as an expert witness in the Sam Mullet / Bergholz case may be seen as motivated by such functionalist logic. Because Bishop Mullet behaved in ways that did not conform to the Ordnung and has, for that reason, been excommunicated, he could no longer be considered Amish.

There is another way of viewing society, in which conflict is normative and constanteven when the society's own ideology understates the existence of conflict or denies its existence. Here, typically, society is seen as dynamic, changing, fluid, ever making new compromises. Whereas "consensus theory" leads to the optimistic or Panglossian view that most cultural traits add to order or solidarity, "conflict theory" makes no a priori judgment about whether society is progressing, puttering along, or going to hell in a hand basket. Scratch a bit under the surface of apparent stasis, and one will find conflict being managed, for the time being. The history of Amish schisms, especially the reactions of Amish authority to the practices of progressive groups, itself belies the consensus view of Amish history and society. Functional explanations tend toward the logical, reasonable, and orderly. But history and social life tend to be a lot more complex and disorderly.

It has been pointed out by many scholars that functionalism often serves as an apologetics for the powerful, and is, as such, complicit in the hegemonic narrative that reproduces structures of power. Those who wield the most power in any society rarely explain their actions or thoughts as being rooted in self-interest or the preservation and aggrandizement of their power. Rather, they claim that their wielding of power adds to the social good—wealthy people are "job creators," the ritual position and work of Brahmins is essential for the well-being of all castes, bishops always make decisions that preserve and defend Amish culture. Because of their focus on the positive virtues of various cultural traits, especially how these traits add to social solidarity and community harmony, functionalist explanations often jibe with those of powerful actors. Other explanatory paradigms tend to be far more likely to get under the surface of the rhetoric of power in order to understand how power operates qua power. This is what some social scientists refer to as attention to "life's hard edges."

But Kraybill's functionalism comes with a more problematic feature that is very different from the perspectives of other social scientists. Most social scientific writing is read by the priesthood of other social scientists, and perhaps (if one is lucky) social science students. 
Kraybill's work, especially Riddle, is read avidly by members of the subject community, in this case, the Amish. Amish who would not themselves be interested in explaining their own riddles, let alone casting a critical gaze upon Amish life, are mostly big fans of Kraybill, largely because he portrays their society and culture in positive ways that seldom challenge authority and received wisdom. One of us (Zook) has been an extremely outspoken critic of Kraybill's shaping of the Amish perspective on their history and culture rather than being a fair-minded analyst of Amish life from multiple perspectives. It is as though Kraybill has conflated the legal roles of expert witness and advocate, which would not be allowed in a court of law. One may hear echoes of Kraybill whenever one engages an Amish person on such topics as the forgiveness narrative, shunning, education, and the Mullet incident.

In addition to satisfying Amish preferences in explaining their lives, there is much about this brand of functionalism that is deeply embedded in wider American cultural predilections. Americans like orderly, rational, plausible sounding explanations for social phenomena rather than references to the vagaries and caprices of history. Determinism suits us better that contingency and probability. ${ }^{6}$ Certainly, we love to think that the highly romanticized Amish do have an underlying rationality to their seemingly inscrutable ways of life. When Billig's family and out-of-town friends come to visit Lancaster, they frequently ask questions about the Amish that begin with, “Why do they...?” or "Why won’t they... ?” Historical answers don’t seem to satisfy them as much as functional ones. Reflecting back on that 19-year-old dazzled by the prospect of a new explanatory science of humanity, I can relate to our cultural biases about what does and does not constitute adequate explanations. And, I must admit, when I first read Kraybill’s Riddle many years ago, I, too, found his explanations deeply satisfying.

Donald Kraybill is popular because he is a fine writer and good scholar who touches the right buttons both for the Amish and for American moderns. But we suspect that many of his explanations are overly facile, out of historical context, and, maybe at times, even dangerous.

\section{Endnotes}

${ }^{1}$ Contact information: Michael S. Billig, Professor and Chair, Department of Anthropology, Franklin \& Marshall College, Lancaster, PA 17604; mbillig@fandm.edu. Elam Zook, Independent Consultant, Department of Anthropology, Franklin \& Marshall College. 421 Nevin St., Lancaster, PA 17603; ezook421@gmail.com

${ }^{2}$ This adjective derives from the character Dr. Pangloss in Voltaire's Candide: Or Optimism. Pangloss is a philosopher who is a parody of Leibnitz and the entire rationalist school of Enlightenment thought. No matter what tragedies befall the characters of the book and the world, Pangloss asserts that things could not be otherwise, because we live in the "best of all possible worlds," which, in Voltaire's view, is a bankrupt philosophy of stasis and inaction. The name "Pangloss" means "all words."

${ }^{3}$ Treating an abstraction or metaphor as a thing of nature capable of exerting action is the classic 
philosophic error of reification, sometimes called the error of misplaced concreteness.

${ }^{4}$ Note the language suggesting the fragility, even tenuousness, of Amish culture.

${ }^{5}$ The argument that the Amish will manage to adapt to this transition without radical changes is more fully made in Kraybill and Nolt (2004).

${ }^{6}$ When Billig was seriously ill 19 years ago, he was surprised at how many people tried to comfort him by saying that "everything happens for a reason." This provided no comfort whatsoever. I just smiled awkwardly and said nothing instead of responding, "Thank you, Dr. Pangloss."

\section{References}

Billig, Michael S. 2003. Barons, Brokers, and Buyers: The Institutions and Cultures of Philippine Sugar. Honolulu, HI: University of Hawaii Press.

Harris, Marvin. 1989. Cows, Pigs, Wars, and Witches: The Riddles of Culture. Reissue edition. New York, NY: Vintage Press.

Harris, Marvin. 2001. Cultural Materialism: The Struggle for a Science of Culture. Updated edition. Lanham, MD: AltaMira Press.

Kraybill, Donald. 2001. The Riddle of Amish Culture. Revised edition. Baltimore, MD: Johns Hopkins University Press.

Kraybill, Donald. and Steven Nolt. 2004. Amish Enterprise. $2^{\text {nd }}$ Edition. Baltimore, MD: Johns Hopkins University Press. 